\title{
Comparison of Loan Payment Models Using Diminishing Balance Interest Rate
}

\author{
APOLINAR T. PAULICAN \\ ORCID No. 0000-0002-4945-8325 \\ polin_poli@yahoo.com \\ Mountain View College \\ Valencia City, Bukidnon, Philippines
}

\begin{abstract}
Lending and borrowing money are ancient practices with specific injunctions for dealing with the borrower given in the Bible. In modern times loans allow the borrower to acquire goods in advance while the lender earns profit through the interest charged. Interest-loaded loans may lead to overspending with financially disastrous consequence for the borrower. In this paper, two models of loan payment, Equal Principal Payment (Model 1) and Equal Installment Payment (Model 2 are presented based on diminishing balance interest rate. The simulated results of the models compared with data provided by a private credit cooperative showed Model 2 to be more realistic, the amount paid comparable with payment to the Credit Cooperative and easy to remember. The interest charged by the private cooperative fluctuated but in a declining pattern while the interest charged in the two models declined continuously, with lesser total interest charged but the difference is not significant. Understanding interest schemes for loan payments may mitigate the danger of financial disaster through overspending.
\end{abstract}

Keywords: Mathematical model, interest, equal installment payment, equal principal payment

\section{INTRODUCTION}

In a person's life, money is very important. Almost every day, money is used in transactions like buying and selling of goods commodities and services. The sale of the exchange of commodities and/or services is called money (Innes, 2013).

In business, lending and borrowing of money are part of the operation where a borrower has the opportunity to use the borrowed money to start or expand 
business or acquire properties. The lender would gain profits through the interest charged. Take for instance in a purchase of item using a credit card. The card provider will lend the money in the form of loan to the costumer in the amount equal to the purchased item. After the agreed period of time, the card holder shall repay all debt obligations to the card provider with the interest. This interest is the payment for borrowing the money.

The payment of borrowed money with interest charged has many schemes. In an online article entitled, Flat versus Declining (2011), it was stressed that paying the interest amount is dependent of the rate agreed and the method used in calculating it. Some lending institutions use interest rate charged to the original borrowed money throughout the term of the loan. This method of calculating the interest is called flat rate method. Others use to calculate the charged interest based only on the money that remains in the hands of the borrower. That is, interest calculation is based on the outstanding loan balance. This method is called diminishing interest rate method.

Comparing the two mentioned method of interest calculations, the later, diminishing interest rate method sounds attractive. However, many of the borrowers have little, if not, no idea about how the repayment of a loan is done using this scheme. In this paper, two systems of repaying a loan using a diminishing interest rate method are mathematically modelled in trying to reveal the repayment contents of a loan.

\section{FRAMEWORK}

Lending and borrowing of money to acquire properties or to start and expand a business is a common practice. However, such lending and borrowing have payment called interest charges. These charges have many possible schemes depending on the approved agreement between the lender and the borrower (Flat versus Declining, 2011). The interest charged in a specified time plus the portion of the barrowed money will constitute an amortization will be paid regularly to the lender until the end of the term of the loan.

The two models of repaying a loan using diminishing interest rate method are considered in this paper: The Equal Principal Payment and Equal Installment Payment. Each of the payment method is mathematically modeled to reveal the behavior of the repayment scheme of a loan. Using numerical simulations, the solutions were determined and the results were graphed.

With the available data from a private Credit Cooperative which uses 
diminishing interest rate, the simulated data from the derived models were compared showing the comparisons.

\section{Model of Personal Loans}

\section{Model 1: Equal Principal Payment}

The basic assumptions under this model are:

i.) Repayment period is pre-determine and is fixed;

ii.) Each payment is done at the end of each period;

iii.) The interest rate does not fluctuate;

iv.) The amount paid for the principal is equally divided for each payment period and fixed.

Let

$\mathrm{P}=$ be the amount of the loan (principal)

$A_{n}=$ be the amount for installment payment

$\mathrm{B}=$ amount paid for the loan (principal) at the end of the period $\mathrm{n}$ is fixed, i.e.,

$B=p / n$

$\mathrm{t}=$ time

$=1$ year

$\mathrm{I}=$ is the interest

$\mathrm{I}=\operatorname{Prt}=\operatorname{Pr}$

Then, at $\mathrm{n}=1$, at the end of the first period, the amount paid for the first installment $A_{1}$ is given by 


$$
\begin{aligned}
& A_{1}=B+I \\
& A_{1}=B+P r
\end{aligned}
$$

At $\mathrm{n}=2$,

Let $P_{l}=P-B$, the new loan amount (principal)

Now

$$
A_{2}=B+P_{1} r
$$

Simplifying (2), we have

$$
A_{2}=B(1-r)+P r
$$

Thus, the general equation of the amount for installment payment $A_{n}$ at any $n$ is given by:

$$
A_{n}=B[1-r(n-1)]+P r
$$

$$
A_{n}=B[1-i(n-1)]+P i
$$

Where simple interest rate $i$, per conversion period is

$$
i=\frac{r}{m}
$$

And the outstanding balance of the loan at term $n, P_{n}$ is

$$
P_{n}=P_{n-1}+I_{n}-A_{n}
$$

Where the interest after the period $n$ is

$$
I_{n}=[P-B(n-1)] i
$$

\section{Model 2: Equal Installment Payment}

In this method, the installment payment $A_{n}$ is fixed while the amount paid for the loan (principal) B at the end of the period $n$ is not fixed. Sirug (2014) claimed that in a series of equal regular payments in a personal or business transactions, the accumulated amount $\boldsymbol{A}$ is also known as future value $F_{n}$ and the principal amount $\boldsymbol{P}$ is known as present value $\boldsymbol{P}_{n}$ and the regular amount paid denoted by $\boldsymbol{R}$ is given by 


$$
P_{n}=A\left[\frac{1-(1+i)^{-n}}{i}\right]
$$

Which follows that the installment payment $A$ is given by

$$
A=\frac{i P}{1-(1+i)^{-n}}
$$

The amount paid for the loan (principal) $B_{n}$, at the end of the period $n$

$$
\begin{aligned}
& B_{n}=A-I_{n} \\
& B_{n}=A-i P_{n-1}
\end{aligned}
$$

And

$$
\begin{aligned}
& P_{n}=P_{n-1}-B_{n} \\
& P_{n}=(1+i) P_{n-1}-A
\end{aligned}
$$

The rate of money growth are anticipated to affect the interest rate in many ways. For instance, if the growth rate of money increases, there is also an excess supply of money in circulation, particularly in homes and the price levels of commodities and services will also rise up. This includes the growing of interest rates in lending institutions. The rising up of interest rates in response to the changing rate of money growth has been an established pattern based on the studies of Cagan (1972), Cagan and Gandolfi (1969), and Gibson (1970).

Interest rate is a crucial factor to lending institutions. This rate is the defining factor as far as the risk of the sustainability of the institution. Delis and Kouretas (2011) found that low-interest rates indeed increase lending institution risktaking substantially. However, the effects of interest rates on lending institution risk-taking is dependent on individual bank characteristics. Lending institutions with higher equity capital has lesser risk-taking than those low equity capital.

\section{OBJECTIVES OF THE STUDY}

The study focused on the mathematical modelling of the two methods of interest calculations using the diminishing interest rates in repaying a loan. However, many of the borrowers have little, if not, no idea about how the repayment of a loan is done using this scheme of a diminishing interest. 
Hence, this paper specifically reveal the repayment contents of a loan using the two diminishing interest rate methods, and are compared with a private credit cooperative which uses diminishing interest rate.

\section{METHODOLOGY}

Two models of repaying a loan using diminishing interest rate method are considered: The Equal Principal Payment and Equal Installment Payment. Each of the method is mathematically modeled in trying to reveal the repayment scheme of a loan. Numerical simulations for their solutions were done and the results were tabulated and graphed. Data from a private Credit Cooperative which uses diminishing interest rate are obtained and graphed. The results of the two models where compared with the data from a private Credit Cooperative in terms of the interest charged and the paid amount.

\section{RESULTS AND DISCUSSION}

\section{Application and Validation of the Model}

Figures 1 to 3 show the behavior of the interest charged of a loan with a term of 60 months ( 5 years) at $1 \%$ interest rate per month.

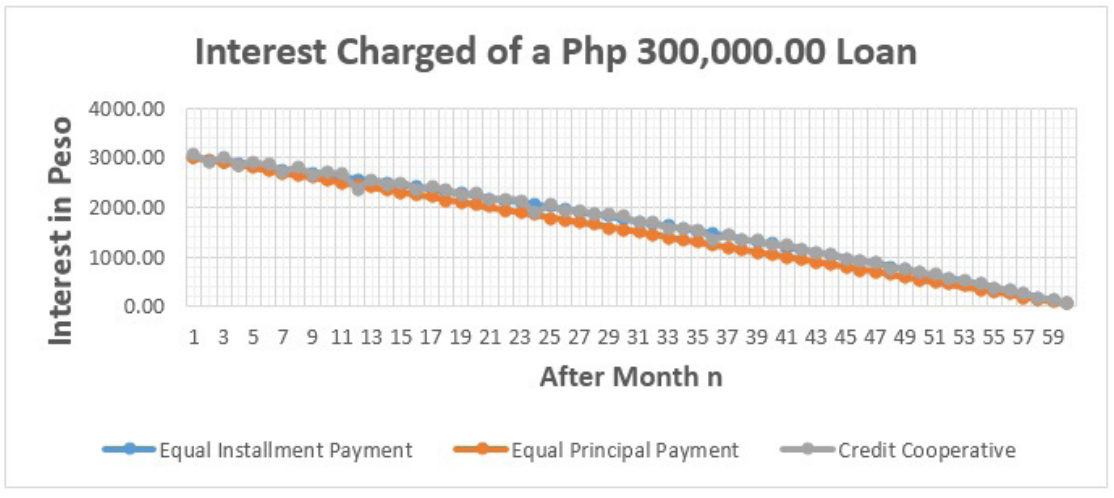

Figure 1. Comparison of Interest Charged of a Php 300,000.00 Loan. 


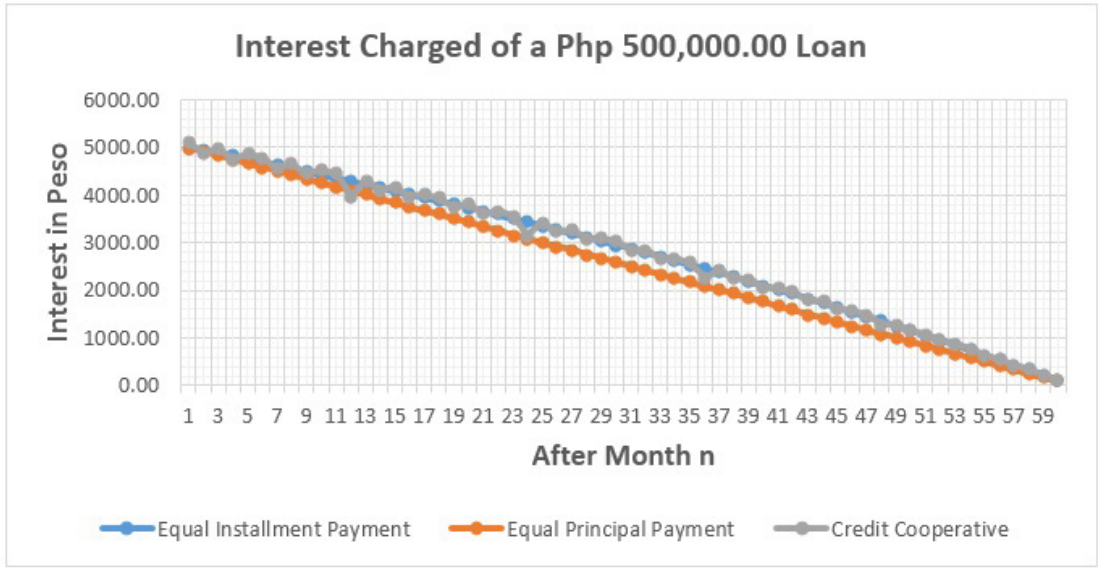

Figure 2. Comparison of Interest Charged of a Php 500,000.00 Loan.

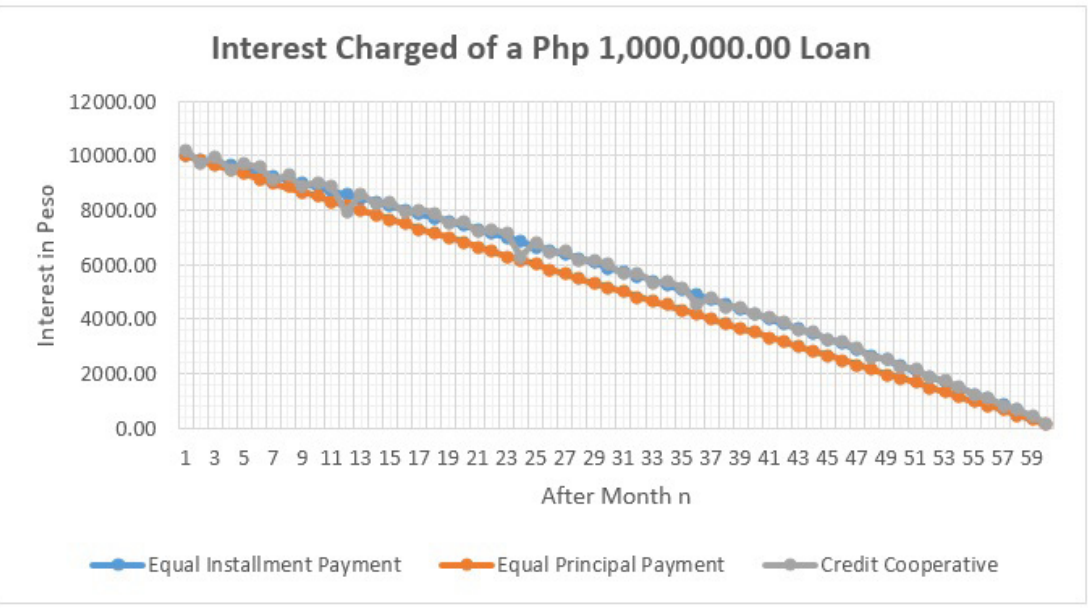

Figure 3. Comparison of Interest Charged of a Php 1,000,000.00 Loan.

Using the data provided by a private Credit Cooperative, the models were compared. As can be seen from the figures, the interest charged by the private cooperative fluctuated but in a declining pattern while the interest charged in the two models declined continuously.

In the simulated data using Model 2, the Equal Installment Payment was realistic because it has approximately the same amount of interest paid with the private credit cooperative. The numeric comparisons of the average and sum of 
interest charged after year one to year five are shown in tables 1 and 2, respectively. It can be seen that although the total interest charged calculated using the models is lesser, the difference is not significant.

Table 1. Comparison of Average Interest Charged (in Peso) of Loans at $1 \%$ per Month Interest Rate

\begin{tabular}{|c|c|c|c|c|c|c|}
\hline \multirow{2}{*}{$\begin{array}{c}\text { Amount of } \\
\text { Loan } \\
\text { (in Peso) }\end{array}$} & \multirow[b]{2}{*}{ Model } & \multicolumn{5}{|c|}{ After Year t } \\
\hline & & 1 & 2 & 3 & 4 & 5 \\
\hline \multirow{5}{*}{$300,000.00$} & Model 1 & $2,725.00$ & $2,425.00$ & $2,125.00$ & $1,825.10$ & $1,525.00$ \\
\hline & Model 2 & $2,791.10$ & $2,544.90$ & $2,277.90$ & $1,988.10$ & $1,673.30$ \\
\hline & Credit Coop & $2,793.40$ & $2,547.40$ & $2,547.40$ & $1,991.50$ & $1,676.90$ \\
\hline & $\mathrm{P}$ - value & 0.534 & 0.321 & 0.304 & 0.382 & 0.552 \\
\hline & Significance & Not Significant & Not Significant & Not Signifícant & Not Significant & Not Significant \\
\hline \multirow{5}{*}{$500,000.00$} & Model 1 & $4,541.70$ & $4,041.70$ & $3,541.70$ & $3,042.00$ & $2,542.00$ \\
\hline & Model 2 & $4,651.80$ & $4,241.50$ & $3,796.50$ & $3,314.00$ & $2,789.00$ \\
\hline & Credit Coop & $4,655.70$ & $4,245.70$ & $3,800.90$ & $3,319.00$ & $2,795.00$ \\
\hline & $\mathrm{P}$-value & 0.534 & 0.321 & 0.304 & 0.382 & 0.552 \\
\hline & Significance & Not Significant & Not Siguificant & Kot Significant & Sot Significant & Not Significant \\
\hline \multirow{5}{*}{$1,000,000.00$} & Model 1 & $9,083.60$ & $8,083.00$ & $7,083.00$ & $5,083.00$ & $5,083.00$ \\
\hline & Model 2 & $9,303.60$ & $8,483.00$ & $7,593.00$ & $5,627.00$ & $5,578.00$ \\
\hline & Credit Coop & $9,311.40$ & $8,491.00$ & $7,601.00$ & $5,638.00$ & $5,589.00$ \\
\hline & $\mathrm{P}$ - value & 0.534 & 0.321 & 0.305 & 0.382 & 0.552 \\
\hline & Significance & Not Significant & Not Siguificant & Not Significant & Tot Significant & Not Significant \\
\hline
\end{tabular}

Table 1 shows the comparison of an average interest charged (in Peso) per month of the loans at $1 \%$ per month interest rate. In the three given amount of loan (in Peso), that is, Php 300,000.00, Php500,000.00 and Php 1,000,000.00, the interest charged in Model 1, which is the Equal Principal Payment is the lowest and the charged by the private Credit Cooperative is the highest from the first year of the loan until the end of the term (in year 5). Comparing the average 
interest charged every year using Analysis of Variance (ANOVA), the difference is not statically significant. Meaning, either of the two derived models or the interest charged by the private credit cooperative, the interest in average is just the same. Specifically, if a borrower has a loan of Php 500,000.00, after year 1, the difference in average charge between Model 1 and the private Credit Cooperative is just Php 114.00 which is $0.0228 \%$ of the borrowed amount. Similarly, after year 5 , the difference is just Php 253.00 which is $0.0506 \%$ of the loan amount.

Table 2. Total Interest Charged (in Peso) of Loans at 1\% per Month Interest Rate.

\begin{tabular}{|c|c|c|c|c|c|c|}
\hline \multirow{2}{*}{$\begin{array}{c}\text { Amount of } \\
\text { Loan } \\
\text { (in Peso) }\end{array}$} & \multirow[b]{2}{*}{ Model } & \multicolumn{5}{|c|}{ After Year t } \\
\hline & & 1 & 2 & 3 & 4 & 5 \\
\hline \multirow[b]{3}{*}{$300,000.00$} & Model 1 & $32,700.00$ & $58,200.00$ & $76,500.00$ & $87,600.00$ & $91,500.00$ \\
\hline & Model 2 & $33,492.94$ & $61,077.47$ & $82,004.26$ & $95,428.94$ & $100,400.06$ \\
\hline & Credit Coop & $33,521.17$ & $61,137.55$ & $82,100.26$ & $95,592.14$ & $100,612.34$ \\
\hline \multirow{3}{*}{$500,000.00$} & Model 1 & $54,100.00$ & $97,000.01$ & $127,500.02$ & $146,000.04$ & $152,500.06$ \\
\hline & Model 2 & $55,821.56$ & $101,795.78$ & $136,673.77$ & $159,048.24$ & $167,333.43$ \\
\hline & Credit Coop & $55,868.64$ & $101,895.95$ & $136,833.81$ & $159,320.28$ & $167,687.26$ \\
\hline \multirow{3}{*}{$1,000,000.00$} & Model 1 & $109,000.00$ & $193,999.99$ & $254,999.98$ & $291,999.96$ & $304,999.94$ \\
\hline & Model 2 & $111,643.13$ & $203,591.57$ & $273,347.53$ & $318,096.47$ & $334,666.86$ \\
\hline & Credit Coop & $111,737.24$ & $203,791.83$ & $273,647.48$ & $318,620.36$ & $335,354.25$ \\
\hline
\end{tabular}

Table 2 shows the comparison of the total interest charged (in Peso) per year of the loans at $1 \%$ per month interest rate. In the three given amount of loan (in Peso), that is, Php 300,000.00, Php500,000.00 and Php 1,000,000.00, the total interest charged in Model 1, which is the Equal Principal Payment is the lowest and the charged by the private Credit Cooperative is the highest from the first year of the loan until the end of the term (in year 5).

\section{CONCLUSIONS}

The interest charged using the two models declined continuously until the end of the term of the loan. However, the interest charged by the Credit Cooperative 
has fluctuations but is in declining pattern. Although the two developed models have lesser total interest charged on the loan, the difference is not significant. Model 2 which is Equal Installment Payment is more realistic than model 1 because it has comparable amount paid to a loan with a Credit Cooperative. Also, the Model 2, Equal Installment Payment is easy to remember than Model 1: Equal Principal Payment in repaying a loan. Interest of loans calculated using Model 2 is expected to aid borrowers in understanding interest schemes for loan payments thereby providing awareness of the potential risk of financial disaster brought about by interest-loaded loans.

\section{LITERATURE CITED}

Cagan, P. (1972). The channels of monetary effects on interest rates. NBER Books.

Cagan, P., \& Gandolfi, A. (1969). The lag in monetary policy as implied by the time pattern of monetary effects on interest rates. The American Economic Review, 59(2), 277-284.

Chan, K. C., Karolyi, G. A., Longstaff, F. A., \& Sanders, A. B. (1992). An empirical comparison of alternative models of the short-term interest rate. The journal of finance, 47(3),1209-1227.

Delis, M. D., \& Kouretas, G. P. (2011). Interest rates and bank risk-taking. Journal of Banking \& Finance, 35(4), 840-855.

Flat vs Declining Balance Interest Rate. (2011). Retrieved on March 3, 2016 from http://www.mftransparency.org/resources/flat-vs-decliningbalance-interest-rate/

Gibson, W. E. (1970). Interest rates and monetary policy. Journal of Political Economy, 78(3), 431-455.

Innes, A. M. (1913). What is money? Banking LJ, 30, 377. 
Li, X. (2011). Mathematical model of housing loans. Modern economy, 2010, 1, 168-170 doi:10.4236/me.2010.13019

Gibson, W. E. (1970). Interest rates and monetary policy. Journal of Political Economy, 78(3), 431-455.

Sirug, W S. (2014). Mathematics of Investment, 3rd Ed. Mindshapers Co., Inc. Manila, Philippines

Smithin, J. (Ed.). (2002). What is money? Routledge. 